\title{
An Alternative Impression Technique for Fabrication of Feeding Appliance for an Infant with Cleft Palate: A Clinical Report
}

\author{
Dhital S ${ }^{1}$, Mathema SRB ${ }^{2}$, Maskey B ${ }^{3}$ \\ ${ }^{1}$ Lecturer, Department of Prosthodontics, Kantipur Dental College, Kathmandu, Nepal \\ ${ }^{2}$ Professor and HOD, Department of Prosthodontics and Maxillofacial Prosthetics, People's Dental College and Hospital \\ ${ }^{3}$ Assistant Professor, Department of Prosthodontics and Maxillofacial Prosthetics, People's Dental College and Hospital
}

\begin{abstract}
Cleft lip and palate is the most common congenital defect of orofacial region, which results in difficulty in feeding, deglutition and speech. Before surgical intervention, feeding appliance is used to restore the palatal cleft and aid in feeding of an infant. The impression procedure during the fabrication of a feeding appliance is a crucial step and selection of impression tray and impression material is a challenging task. This article attempts to briefly describe an alternative technique for making impression in infants with cleft palate.
\end{abstract}

Key words: Cleft; Feeding appliance, Infant

\section{Introduction}

$\mathrm{C}$ lefts of the lip and palate are common congenital abnormalities involving the orofacial region. The oro-nasal communication due to the defect poses great challenge in feeding, mastication, deglutition, and speech. ${ }^{1}$ It also effects the facial growth and dentition and creates social and psychological problems to the parents. ${ }^{2}$ Inadequate feeding in infants is a major problem because of the inability to produce the necessary negative pressure in the oral cavity due to an opening in the roof of the mouth. ${ }^{3-5}$ This problem is further complicated by nasal regurgitation of food and excessive air intake. ${ }^{6-8}$

The defect can be surgically corrected but timing of surgery ranges from 3 to 18 months, depending

\section{*Corresponding Author}

Dr. Shaishab Dhital, Lecturer

Department of Prosthodontics

Kantipur Dental College, Kathmandu, Nepal

E-mail: shaishavdhital@gmail.com on the severity of the defect. ${ }^{2}$ Sufficient nutrition of the infant is very important before surgical procedure for normal growth and to prepare him/her for surgery . ${ }^{5} \mathrm{~A}$ feeding appliance is a favorable option in such cases as it obturates the cleft area and creates a stable platform toward which the baby can press the nipple and extract milk. ${ }^{9}$ Various types of feeding plate like passive plates, molding plates, and Latham's obturator are available to assist in feeding. ${ }^{10}$ The feeding appliance does not alter the dimensions of the cleft but provide a "false palate" for the infant and permit functions like swallowing and feeding in a more normal manner. ${ }^{11}$ The feeding appliance also prevents cleft widening due to the activity of the tongue and corrects tongue function, leading to the development of speech, providing positive guidance for growth and development of the maxillary segments, and have a positive psychological effect, at least on the parents. . $^{3,5,12,13}$

The impression procedure during the fabrication of a feeding appliance is a crucial step and patient positioning, selection of impression tray and impression materials should thus be 
considered carefully. ${ }^{13,14}$ The impression tray should be of enough size transversely, to include the lateral maxillary segments, to posteriorly cover up to the maxillary tuberosities and to provide a good reproduction of the mucobuccal folds. ${ }^{2}$ Therefore, an individualised impression tray is necessary as a prefabricated commercial tray may not always be useful for obtaining an impression of the infant's maxillary arch due to anatomical variation associated with cleft severity. ${ }^{15,16}$ Thus, the use of several alternative tray designs such as those based on ice-cream sticks, 2 stock poly (methyl methacrylate) impression trays, wax, light-polymerising acrylic resins, perforated metal teaspoon, handle of prefabricated metal tray and fingers has been reported for obtaining impressions in infants with cleft lip and palate. ${ }^{13,14,17-19}$ In this case report, an overview of management of cleft palate patient with emphasis on impression making procedure for the fabrication of feeding appliance is described.

\section{Clinical Report}

A 4-days-old male infant with cleft palate was referred to the Department of Prosthodontics and Maxillofacial Prosthetics, People's Dental College and Hospital, Kathmandu, Nepal for the fabrication of feeding appliance, as the infant had difficulty in suckling milk. The infant was born full-term, weighing $2.4 \mathrm{~kg}$, and had no family history of cleft or any other congenital defect. The intra-oral examination revealed isolated palatal cleft involving hard and soft palate without involving lip and alveolus (Veau class II) (Fig. 1). ${ }^{20}$ After a complete review of the infant's history and oral examination, fabrication of a feeding appliance was decided with parent's approval to improve his vital functions.

The infant was placed in a prone position to avoid aspiration of the impression material and any sort of airway obstruction. Available stock impression trays were not appropriate for making impression of the infant's oral cavity. Thus, a sterilised plastic teaspoon was used for making impression. First of all the plastic teaspoon was trimmed according to the tentative size of the infant maxillary arch and then modified with autopolymerizing acrylic resin (Rapid Repair, Pyrex, India) with perforations to aid in retention of impression material (Fig. 2). Heavy-body silicone impression material (elite HD+, Zhermack, Italy) was loaded into the modified plastic teaspoon tray; after the material had set fully, the tray was removed from the oral cavity (Fig. 3). While making impression, the infant's crying was observed to rule out any airway obstruction. The beading of impression was done with dental plaster and pumice and boxing was done with modelling wax (Modelling Wax, Pyrex, India) (Fig. 4) and then poured with type IV dental stone (Ultrarock, Kalabhai Karson Pvt. Ltd, Mumbai, India) and cast was obtained (Fig. 5). The wax pattern was made with modelling wax (Modelling Wax, Pyrex, India) (Fig. 6). A feeding plate was then fabricated from heat-polymerised clear polymethacrylate resin (Trevalon/Universal Clear, Dentsply India, India) by using a long curing cycle to minimize the leaching out of the residual monomer and finishing and polishing was done in conventional manner (Fig 7 and 8). Dental floss was then attached onto the feeding appliance to provide a safety mechanism in case of gagging or accidental swallowing (Fig 8).

The feeding appliance was then inserted intraorally to evaluate fit and retention (Fig. 9). After the fit of the appliance was optimal, the response of the infant was observed for few hours. The infant was irritated initially after insertion but after a while mother was able to feed the infant with excellent adaptation of the prosthesis. Proper instructions about appliance insertion and removal, feeding techniques, and cleaning were given to the parents. The mother 
had gained satisfactory nursing experience as well as weight gain of infant was within normal limits during his follow-up visits. Every alternate day during first week after insertion, the infant was monitored for possible tissue

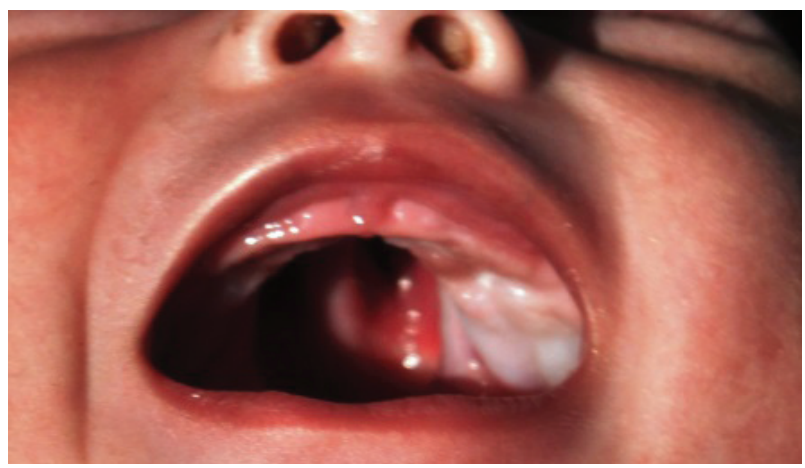

Figure 1: Intraoral view

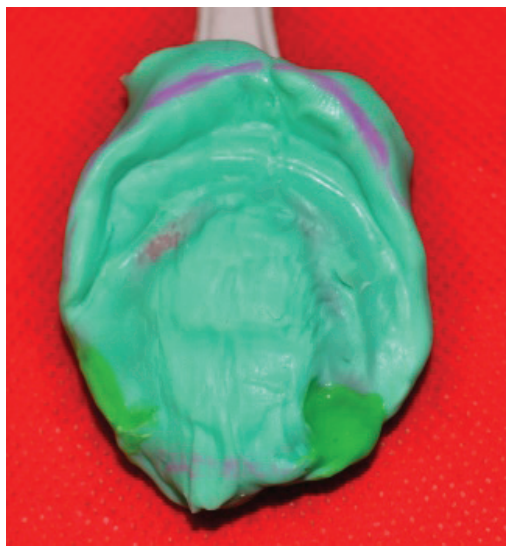

Figure 3.Impression with heavybody silicone impression material

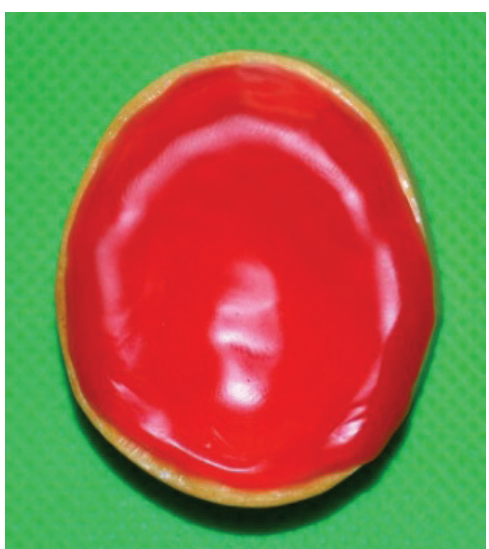

Figure 6: Wax pattern

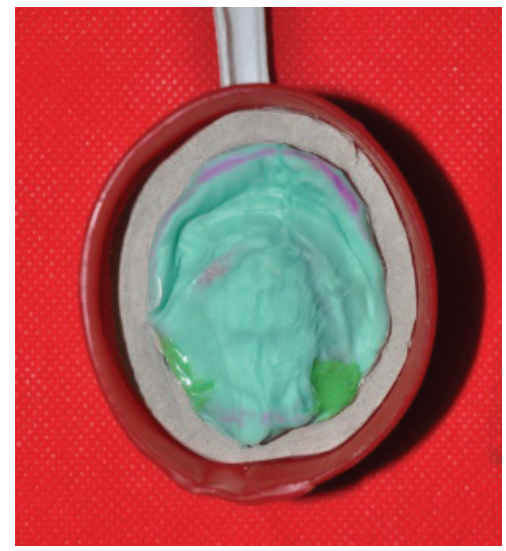

Figure 4: Beadingand boxing of impression

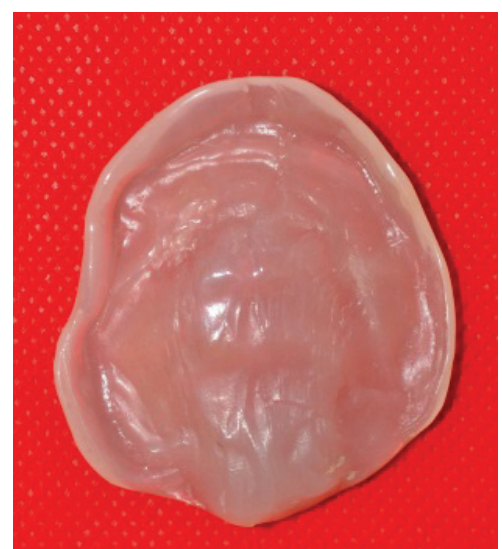

Figure 7: Intaglio surface of feeding appliance irritation. The feeding appliance was adjusted every 2 weeks afterwards and was subsequently replaced with a new one after 2 months as the retention was not optimal and it might hinder the growth of the arch.

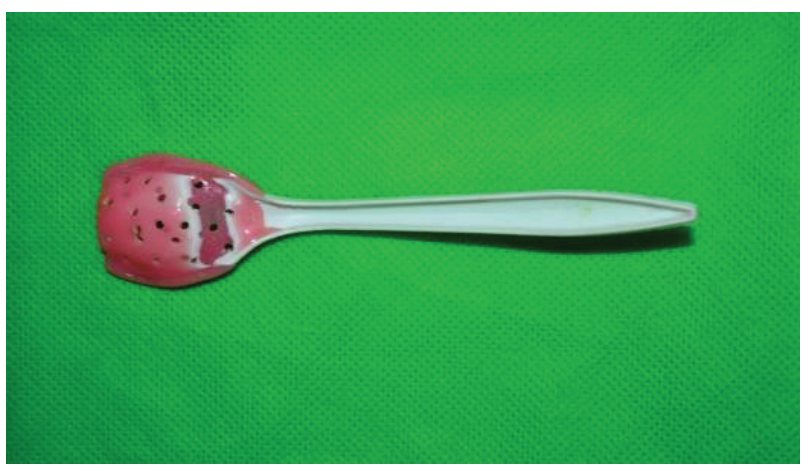

Figure 2: Modified plastic tea-spoon impression with autopolymerizing acrylic resin

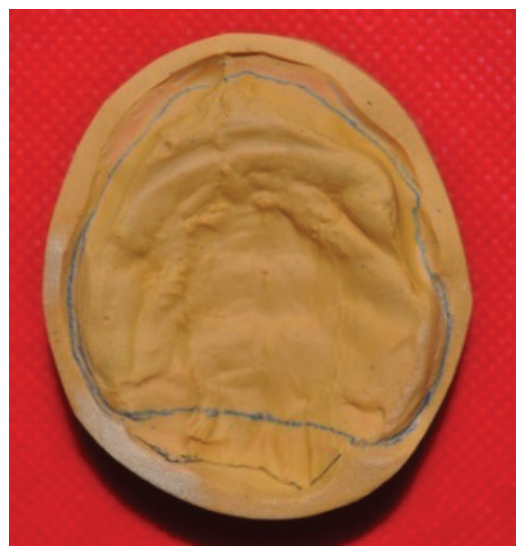

Figure 5: Cast with defect

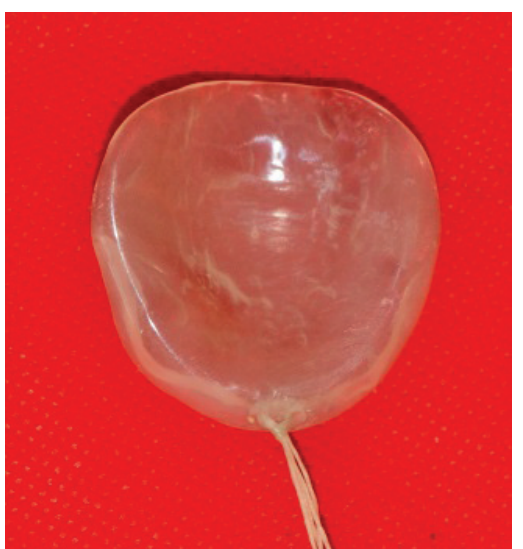

Figure 8: Polished surfaceof feeding appliance with dental floss tied 


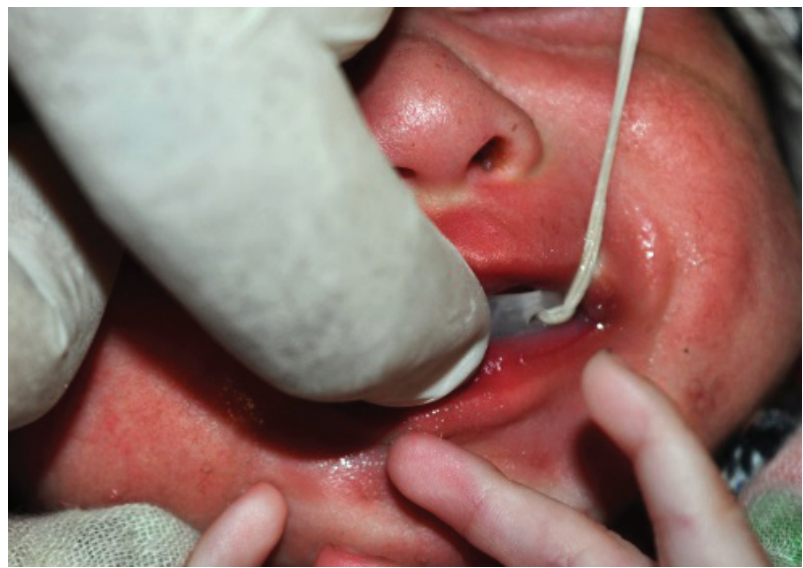

Figure 9: Feeding appliance delivery

\section{Discussion}

An accurate impression of the cleft maxilla is essential for fabrication of feeding appliance that is well adapted to the patient's anatomical structures. ${ }^{16}$ Impression procedures in infant with cleft palate poses a great challenges due to anatomical variation in cleft size, lack of infant cooperation, inadequate size of oral cavity, the need to obtain an impression within a short period of time, retention of the impression material in the tray, and the selection of an impression tray and materials. ${ }^{19}$

In the presented case, a plastic teaspoon was used and modified with autopolymerizing acrylic resin according to infant's intraoral condition. Rimming of the entire tray with autopolymerizing acrylic resin provides an additional bulk of material laterally, to avoid the sharp edges of the tray and also to provide a posterior dam to prevent the material from seeping posteriorly. ${ }^{17}$ The perforation made enabled proper retention of the impression material in the tray. It also allowed excess impression material to pass through the perforations without pressure from oral tissue, preventing the flow of impression material to the posterior airway region. ${ }^{19}$ In this way, the possible risk of airway blockage with impression material, the most important potential complication of the impression procedure, was eliminated through controlled impression technique. Heavy-body silicone impression material was used due to its superior properties over other impression materials. ${ }^{10}$

The modified plastic spoon tray is discarded after its use, preventing any risk of cross infection. The modified plastic spoon tray described in this report is readily available and cost effective. In addition, it can be trimmed and modified easily depending upon the clinical conditions. Another advantage is that in many instances the fabrication of individualized tray may not be required as it can be customized according to infant's intraoral condition which reduces the clinical and the laboratory hours and the number of visits. Although this procedure is not applicable in all the cases, it can be considered as an alternative method of obtaining an initial or the final impression.

\section{Summary}

The modified plastic teaspoon tray described in this clinical report is readily available, cost effective and can be modified easily. It can be used as an alternative method to make initial or final impression in the infant with clefts.

\section{References}

1. Mossey PA, Little J, Munger RG, Dixon MJ, Shaw WC. Cleft lip and palate. The Lancet. 2009;374(9703):1773-1785.

2. Rizwaan A, Sujoy B, Rajlakshmi B, Atif K. Prosthetic rehabilitation of cleft compromised newborns: a review. J Clin Diagn Res. 2010;4:3632-3638.

3. Jiri B, Jana V, Michal J, et al. Successful early neonatal repair of cleft lip within first 8 days of life. Int J Ped Otorhinolaryngology. 2012;76(11):1616-1626.

4. Reid J. A review of feeding interventions for infants with cleft palate. The Cleft palateCraniofacial J 2004;41(3):268-278.

5. Erkan M, Karaçay Ş, Atay A, Günay Y. A modified feeding plate for a newborn with cleft palate. The Cleft Palate-Craniofacial J. 2013;50(1):109-112. 
6. Osuji OO. Preparation of feeding obturators for infants with cleft lip and palate. The Journal of Clin Ped Dent. 1995;19(3):211-214.

7. Goldberg WB, Ferguson FS, Miles RJ. Successful use of a feeding obturator for an infant with a cleft palate. Special Care Dent 1988;8(2):86-89.

8. Saunders I, Geary L, Fleming P, Gregg T. A simplified feeding appliance for the infant with a cleft lip and palate. Quint Int (Berlin, Germany: 1985). 1989;20(12):907.

9. Bargale S, Sikligar S, Shah S, Mulchandani V, Rachappa M, Dave B. A ray of hope in cleft lip and palate patients case reports. European J Dent Therapy Res. 2014;3(2):217-220.

10. Sabarinath V, Hazarey $P$, Ramakrishna Y, Vasanth R, Girish K. Caring for cleft lip and palate infants: Impression procedures and appliances in use. J Ind Prosthodont Soc. 2009;9(2):76.

11. Proffit WR, Fields Jr HW, Sarver DM. Contemporary orthodontics: Elsevier Health Sciences; 2006.

12. Karayazgan B, Gunay Y, Gurbuzer B, Erkan M, Atay A. A preoperative appliance for a newborn with cleft palate. The Cleft Palate-Craniofacial J. 2009;46(1):53-57.

13. Ravichandra K, Vijayaprasad K, Vasa A, Suzan $\mathrm{S}$. A new technique of impression making for an obturator in cleft lip and palate patient. J Ind Soc Pedodont Preventive Dent. 2010;28(4):311.

14. Grayson BH, Shetye PR. Presurgical nasoalveolar moulding treatment in cleft lip and palate patients. Ind J Plastic Surg. 2009;42(Suppl):S56.

15. Prahl-Andersen B. Dental treatment of predental and infant patients with clefts and craniofacial anomalies. The Cleft palate-craniofacial J. 2000;37(6):528-532.

16. Strobel-Schwarthoff K, Hirschfelder U, Hofmann E. Individualized erlanger KSimpression trays for infants with cleft lip and palate. The Cleft palate-craniofacial J. 2012;49(2):237-239.

17. Jacobson BN, Rosenstein SW. Early maxillary orthopedics for the newborn cleft lip and palate patient: An impression and an appliance. The Angle Orthodontist. 1984;54(3):247-263.

18. Jones JE, Henderson L, Avery DR. Use of a feeding obturator for infants with severe cleft lip and palate. Special Care in Dent. 1982;2(3):116-120.

19. Akay C, Karakis D, Yalug S. An alternative impression technique for an infant with cleft palate. Int Dent Res. 2015;5:38-41.

20. Veau V, Borel S. Division palatine: anatomie, chirurgie, phonetique; avec la collaboration de S. Borel: Masson; 1931. 